\title{
Pharmacy-based alcohol-misuse services: current perspectives
}

This article was published in the following Dove Press journal: Integrated Pharmacy Research and Practice

\author{
Hendrika L Hattingh' \\ Robert J Tait ${ }^{2}$ \\ 'School of Pharmacy and \\ Pharmacology, Griffith Health, \\ Griffith University, Gold Coast, QLD, \\ ${ }^{2}$ National Drug Research Institute, \\ Faculty of Health Sciences, Curtin \\ University, Perth, WA, Australia
}

Context: Globally, the use of alcohol is a leading cause of mortality and morbidity. Opportunistic screening and brief interventions (SBIs) have been shown to be effective in reducing alcohol consumption in certain primary care settings and provide a means of reaching some of those who do not seek treatment for alcohol-related problems. Further, community pharmacies have the potential to reach consumers at an early stage of their alcohol use and incorporate intervention and advice into their role in providing medications.

Aim: The purpose of this review was to inform pharmacists and stakeholders of the evidence base for SBI in community pharmacy settings. To date, there has been limited research on the effectiveness of alcohol SBI in community pharmacies, with a systemic review only identifying two randomized trials.

Methods: This narrative review reports on the period 2007-2017, covering feasibility studies, pilot programs, and surveys of consumers and pharmacy staff attitudes relating to alcohol SBI in this setting. Studies were identified via MEDLINE, CINAHL, Google Scholar, and reference lists of relevant publications.

Findings: The findings indicated that the provision of community pharmacy alcohol SBI requires training in communication and intervention skills and in some cases increasing confidence and alcohol-related knowledge. Consumers were generally receptive to the SBI approach but requested private areas for delivery of such.

Conclusion: The high prevalence of "at risk" alcohol use in many countries and the low level of treatment seeking by this group means that novel approaches to engage opportunistically with these people is imperative in reducing alcohol-related harms. However, before committing routine health funding, these novel approaches need rigorous evaluation.

Keywords: alcohol, brief intervention, screening, community pharmacy, review, primary care

\section{Introduction}

Alcohol is a leading cause of preventable harm internationally, in 2012, causing 3.3 million deaths and the loss of 139 million disability-adjusted life years or $5.1 \%$ of global disease burden. ${ }^{1}$ Due to its prevalence, risky or subclinical levels of drinking are responsible for more harms than alcohol-use disorders. ${ }^{2,3}$ However, few people using alcohol in a risky manner, or even those with an alcohol disorder, seek help. ${ }^{4-6}$ The provision of alcohol advice, for example, provided through opportunistic screening and brief intervention (SBI), has proven successful in primary care settings in reducing alcohol consumption and alcohol-related harms. ${ }^{7}$ This creates an opportunity for community pharmacies, as pharmacy staff have regular contact with consumers who have health conditions caused or exacerbated by alcohol use. Community pharmacists
Correspondence: Hendrika L Hattingh School of Pharmacy and Pharmacology, Griffith Health, Griffith University, Parklands Drive, Southport, QLD 4215, Australia

Tel +6I 75552974 I

Email l.hattingh@griffith.edu.au 
are thus well placed to provide alcohol-misuse services and support.

The hazardous and harmful use of alcohol had been classified by the World Health Organization (WHO) as one of the most important risks to health. ${ }^{8}$ The 2014 WHO report Global Status Report on Alcohol and Health confirmed that risky alcohol consumption is problematic in both developed and developing countries. ${ }^{1}$ For example, in Australia, alcohol consumption is estimated to cause $3.2 \%$ of the total burden of disease. Including harms to nonusers, it contributes about 188,000 disability-adjusted life years, causes 5,550 deaths, and costs $\sim$ AU $\$ 30$ billion per year. ${ }^{9,10}$ Australian guidelines provide recommendations for the adult population to reduce the risk of alcohol-related harm. ${ }^{11}$ Still, considered against the guidelines, in 2016 , about $17 \%$ of adults were "at-risk" from their average alcohol consumption (more than two standard drinks per day), about $26 \%$ from single occasion use (more than four standard drinks at an occasion), and 37\% from either single occasion or average use. ${ }^{12}$ Further, about 3.9\% and $1.4 \%$ of the population fulfill the criteria for an alcohol disorder (harmful use or dependence) ${ }^{13}$ (see Box 1).

Alcohol use is implicated in a wide range of conditions, including cardiovascular disease, many cancers, diabetes, overweight, and obesity. ${ }^{11}$ Previous assumptions that moderate alcohol use was protective for some conditions, in particular cardiovascular disease, is now suggested to be an artifact of observational studies. ${ }^{14}$ Opportunistic screening can be used to identify those "at risk" of alcohol-related harms, and universal screening is recommended in primarycare settings and emergency departments. ${ }^{2}$

Community pharmacy staff are often the first point of contact for consumers accessing the health-care system. ${ }^{15}$ Pharmacy staff regularly assist consumers with the management

\section{Box I Common alcohol terminology}

I. Risky drinking: a specific term for a pattern or level of drinking associated with increased risk of alcohol-related harms

2. Hazardous use: currently used by the World Health Organization (but not a diagnostic category) to denote a pattern of use that increases the risk to the user; most notably used in the Alcohol Use Disorders Identification Test (AUDIT) for those scoring $\geq 8$ or more

3. Harmful use: International Classification of Disease (ICD)- 10 diagnosis where use is causing social, physical, or mental harms

4. Dependent use: ICD-IO diagnosis that requires three or more criteria to be fulfilled (eg, tolerance, inability to control use, compulsion to use, withdrawal state, preoccupation with use, and use despite harms)

5. Dependent use: DSM5-classified as mild, moderate, or severe, depending on the number of symptoms present

Note: Data from the World Health Organization ${ }^{100,101}$ and the American Psychiatric Association. ${ }^{102}$ of minor, self-limiting symptoms ${ }^{16,17}$ that could be associated with inappropriate alcohol use (ie, indigestion, vomiting, diarrhea, headaches, sleeping irregularities, requests for hangover management). ${ }^{18}$ Requests for emergency contraception also provide an opportunity to explore alcohol use. ${ }^{19}$ Additionally, pharmacists have regular contact with consumers with chronic conditions through the dispensing of repeat prescriptions to manage these conditions..$^{20,21}$

Community pharmacists are thus well placed to play a role in the early intervention process through provision of alcohol-misuse services, such as SBI and provision of ongoing support. Pharmacists and pharmacy staff have the opportunity to identify consumers who may have risky drinking behaviors, with the potential to educate them about alcohol use. This presents a unique opportunity for community pharmacists to discuss alcohol-related matters, illness, and relevant social issues with consumers and provide information and facilitate referrals. The WHO report on strategies for implementing early identification and alcohol-focused interventions in primary health care emphasized the variety of locations in which alcohol services, such as brief intervention (BI), can be provided. ${ }^{22}$ Community pharmacy staff are in an ideal situation to complement services provided by general practitioners (GPs) or hospital emergency departments and contribute to alcohol awareness.

\section{Objective}

A recent systematic review and meta-analysis of community pharmacy interventions for smoking cessation, weight management, and alcohol reduction identified only two studies addressing alcohol use that fulfilled their inclusion criteria. ${ }^{23}$ The objective of this review was to identify and evaluate the broader available literature on community pharmacy alcoholmisuse services.

\section{Methods}

This narrative literature review provides a summary of the role of community pharmacists in addressing alcohol misuse through integration with other professional activities. This is followed by a review of the literature on the role of community pharmacists in alcohol intervention studies. This review also provides an overview of key alcohol SBI studies.

The review of the role of community pharmacists in alcohol intervention studies involved searching CINAHL, Medline, and Google Scholar for the period 2007-2017 using the search terms "alcohol", "alcohol misuse", "alcohol intervention", and "community pharmacy" to identify articles on the role of pharmacists in alcohol-misuse services. Literature 
on the role of community pharmacists in alcohol-intervention studies focused on reports published after 2007: the interval since the last systematic review focused specifically on alcohol services in community pharmacies. ${ }^{24}$ Studies that involved pharmacists in other settings (ie, hospital pharmacies) were excluded. As searching of databases resulted in a limited number of studies, a snowballing process was also followed, whereby the reference lists of relevant articles were scanned to identify more publications. Gray literature was also identified through generic search engines.

This narrative review was undertaken in the context of the WHO report on strategies for implementing early intervention at the primary health level, ${ }^{22}$ the changing landscape of community pharmacy with regard to the provision of patient care services and chronic disease management, ${ }^{25}$ and community pharmacists being ideally positioned to provide support to consumers with mental health illness, including alcohol misuse, at the primary health-care level. ${ }^{26}$

\section{Results}

\section{Role of community pharmacists in addressing alcohol use}

Pharmacists have regular contact with consumers with chronic conditions through dispensing services, which provide opportunities to screen and educate them about various health-related issues, including alcohol use. Certain medical conditions, such as peptic ulcer disease and diabetes, require an understanding of the risks involved with alcohol consumption, such as increased risk of ulcer bleeding and hypoglycemia. ${ }^{1,27}$ Long-term harmful drinking may contribute to the development of chronic conditions, such as cardiovascular disease, cirrhosis of the liver, dementia, mental health problems, and cancer. ${ }^{28}$ Of specific relevance is the comorbidity or the co-occurrence of alcohol-use disorders and other mental disorders, which can be a major challenge in treating either problem. ${ }^{29}$ For example, the seminal US Epidemiologic Catchment Area study found that among those with an alcohol disorder, the lifetime prevalence of any (nonsubstance use) mental health disorder was $36 \%$ (OR 2.3 compared to those without an alcohol disorder). ${ }^{30}$ In Australia, $35 \%$ of those with a substance-use disorder in the previous 12 months also had another mental disorder, ${ }^{31}$ with a 2014 Australian Institute of Health and Welfare report indicating 31.1 million government-subsidized mental health prescriptions dispensed in 2012-2013, accounting for $11.4 \%$ of all prescriptions. ${ }^{21}$

Medication interactions with alcohol are particularly risky in older adults, due to the high incidence of multiple comorbidities, physiological changes, ${ }^{32,33}$ and increased risk of falls. ${ }^{34}$ Certain medicines are specifically contraindicated with alcohol and can cause a disulfiram-type reaction (ie, metronidazole) or falls due to increased drowsiness, eg, certain antipsychotics, hypnotics, and opioid analgesics. ${ }^{27}$ Pharmacists should attach cautionary advisory labels when dispensing and counsel consumers about the impact of alcohol on their medicines. ${ }^{18}$ However, despite these issues, a 2005 Australian survey of 816 adults showed that concurrent use of medicines and alcohol was common. ${ }^{35}$ A more recent survey of 188 adults aged $60-89$ years showed that very few recalled a discussion with their pharmacists in the previous 12 months about alcohol use, but much higher percentages recalled discussions with their GPs. ${ }^{36}$ Of significance was that $50 \%$ of the men and $63 \%$ of the women believed it appropriate for pharmacists to ask about alcohol use, showing a need to increase community pharmacists' awareness of the need to discuss alcohol use with consumers.

Community pharmacists provide a wide range of primary health-care services and interventions, ${ }^{20,37-39}$ with research showing positive consumer health outcomes. ${ }^{40-44}$ Trials and observational studies have provided evidence of the clinical efficacy and cost-effectiveness of community pharmacy-led smoking cessation ${ }^{23}$ and lipid management interventions in the reduction of risky behaviors and risk factors for coronary heart disease. ${ }^{45}$ There is also evidence for positive outcomes when pharmacists support consumers with mild-moderate mental illnesses. ${ }^{46}$

The positive impact of pharmacist interventions to assist consumers with smoking cessation ${ }^{47-49}$ has resulted in many pharmacies providing smoking cessation advice as part of normal practice. A scoping review about the role of community pharmacists in public health identified a wide range of services provided, with one of the dominant themes being prevention of drug-related problems and addiction. ${ }^{50} \mathrm{~A}$ study among the general public in the UK showed people were receptive to pharmacy public health services. ${ }^{51}$ However, the role of community pharmacy in public health promotion seems to be underutilized in some countries, ${ }^{52}$ and a specific need has been identified to include community pharmacies as part of strategies to address excessive alcohol use. ${ }^{24}$

\section{Targeted community pharmacy alcohol- misuse services}

The role of the community pharmacy in provision of alcohol services is new compared with other professional services. Only two systematic reviews were identified about the effectiveness of community pharmacy alcohol interven- 
tions. A review conducted by Watson and Blenkinsopp that incorporated the period 1996-2007 identified three feasibility studies involving 14 pharmacies and 500 customers. ${ }^{24}$ The authors concluded that there was little empirical evaluation of the impact of community pharmacy-based alcohol-misuse services and that large-scale studies were needed. A more recent systematic review by Brown et al that included articles up to May 2014 about the effectiveness of community pharmacy-delivered interventions for alcohol reduction, smoking cessation, and weight management identified two randomized controlled trials (RCTs) on community pharmacy alcoholreduction interventions. ${ }^{23}$ Both these RCTs were conducted in the UK, with Watson et $\mathrm{al}^{53}$ using the Fast Alcohol Screening Tool, whereas Dhital et $\mathrm{al}^{54}$ used the Alcohol Use Disorders Identification Test (AUDIT). The studies involved 36 pharmacies and 476 customers. Evidence about the impact of the pharmacist interventions from both studies was limited, and the authors recommended that further research was required on the cost-effectiveness of community pharmacy-delivered alcohol-misuse services.

In addition to the RCTs identified in the Brown et al review, a number of other recent (post-2007) studies have focused on the feasibility, effectiveness, and acceptability of community pharmacy-based alcohol-misuse services from both consumers' and pharmacists' perspectives. Identified studies were conducted in the UK and New Zealand (NZ) and more recently in Australia. Table 1 provides a summary of these studies.

A study by Sheridan et al that involved a survey of 2,384 NZ pharmacy consumers from 43 pharmacies showed positive consumer attitudes to pharmacists undertaking SBI, with $\sim 30 \%$ of participants with at-risk drinking who could benefit from a pharmacy intervention. ${ }^{55}$ Research by Fitzgerald et al based in Scotland, which involved a 2-day training course of 22 pharmacy staff from the Greater Glasgow area in alcohol screening and intervention, recruited 70 consumers, with 30 screened as drinking hazardously and seven at harmful levels. ${ }^{56}$ Consumers received such interventions as explanation of "low-risk" drinking, feedback on screening, and risks to health. On follow-up, consumers were generally positive about the pharmacy intervention, and pharmacists perceived the project as worthwhile. ${ }^{57}$ A study by Brown et al in North East England that focused on women who accessed community pharmacies for emergency contraception showed that some pharmacists felt uncertain about engaging consumers in conversations about sensitive topics, although interviews with the consumers themselves showed that they were not embarrassed, appreciated receiving advice, and felt that a pharmacist was an appropriate person to carry out alcohol screening and provide advice. ${ }^{58}$

Dhital et al have been involved in a number of studies in the UK. A 2008 London study with 237 participants from four pharmacies indicated high consumer willingness to participate in SBI and follow-up appointments with the pharmacist. ${ }^{59}$ Pharmacists were considered more accessible to the public than GPs, although there were concerns whether pharmacists were knowledgeable or had suitable training to conduct SBI. The London researchers conducted a subsequent pre and postexperimental study involving 141 consumers from 26 community pharmacies, during which $75 \%$ of the participants were identified as risky drinkers. Three-month follow-up interviews with hazardous drinkers found that they significantly reduced their alcohol consumption and drinking days, although there was no difference in AUDIT-C (alcohol-consumption questions from the full AUDIT) scores. ${ }^{60}$ The results from this study were used to design a two-arm RCT. ${ }^{61}$ However, the RCT conducted in London between May 2012 and May 2013 that involved 407 pharmacy consumers did not show any difference at 3 -month follow-up between the intervention $(n=205)$ and control $(n=202)$ groups in terms of drinking behavior. The authors concluded that the pharmacists were undertrained in delivering BIs, as they had only received 3.5 hours of training, and it was hence recommended that training should be more comprehensive and incorporate communication approaches and motivational interviewing. ${ }^{54}$

Another UK study by Krska and Mackridge ${ }^{62}$ conducted in North West England involved interviewing 150 consumers about their perspectives on community pharmacy-based alcohol services. A focus group was subsequently conducted to obtain input into the design of an alcohol SBI pilot study. Five pharmacies screened 164 consumers over a 2-month period using AUDIT. Of those consumers, 113 were lowrisk, 24 increased-risk, and 28 high-risk/possibly dependent drinkers. Ten of the service users interviewed considered the experience positive but wanted the service to be delivered in a private area.

A Western Australian feasibility study by Hattingh et al conducted toward the end of 2014 involved five community pharmacies in Perth enrolling and screening 50 consumers in total. ${ }^{63}$ Pharmacists already had motivational interviewing skills, ${ }^{46}$ and two pharmacists at each pharmacy received face-to-face training in alcohol SBI by an experienced pharmacist who also acted as a mentor throughout the project. From the consumers' AUDIT scores, 11 were categorized as "hazardous" (score 8-15), 4 as "harmful" (score 16-19), 
Table I Overview of community pharmacy alcohol-misuse intervention studies

\begin{tabular}{|c|c|c|c|}
\hline Study design & Short description of research & Country & References \\
\hline Focus groups & $\begin{array}{l}\text { Two focus groups conducted with } 14 \text { community pharmacists. Participants } \\
\text { acknowledged alcohol advice as part of role but identified need to increase knowledge, } \\
\text { skills, and confidence }\end{array}$ & Australia & Dare et $\mathrm{a}^{67}$ \\
\hline $\begin{array}{l}\text { Mixed methods: } \\
\text { survey and } \\
\text { interviews }\end{array}$ & $\begin{array}{l}\text { Five pharmacies provided SBI to } 50 \text { consumers who completed AUDIT. Post-SBI } \\
\text { survey and 3-month follow-up interviews showed acceptability of service. Ten } \\
\text { pharmacists interviewed were positive about service }\end{array}$ & Australia & Hattingh et $\mathrm{a}^{63}$ \\
\hline Survey & $\begin{array}{l}\text { One hundred and eighty-eight people aged }>60 \text { years responded. } 50 \% \text { of men and } \\
65 \% \text { of women were receptive to having alcohol-related health conversations with } \\
\text { community pharmacists }\end{array}$ & Australia & Wilkinson et $\mathrm{a}^{36}$ \\
\hline $\begin{array}{l}\text { Randomized } \\
\text { controlled trial }\end{array}$ & $\begin{array}{l}\text { Parallel group randomized trial involved } 16 \text { community pharmacies and } 407 \text { pharmacy } \\
\text { customers in London. Customers completed AUDIT; those who scored 8-19 were } \\
\text { allocated to SBI or leaflet. At } 3 \text { months, } 326 \text { participants were followed up. SBI } \\
\text { appeared to have no effect, and follow-up interactions recommended }\end{array}$ & UK & Dhital et $\mathrm{al}^{54}$ \\
\hline $\begin{array}{l}\text { Mixed methods: } \\
\text { interviews, } \\
\text { focus group, and } \\
\text { observation }\end{array}$ & $\begin{array}{l}\text { Face-to-face survey of I } 50 \text { consumers about pharmacy-based alcohol services } \\
\text { incorporated FAST. Nine participants of focus group to design a service. Five } \\
\text { pharmacies participated in } 2 \text {-month pilot of } 164 \text { screenings, with 15\% AUDIT score of } \\
\text { increased risk, I2\% high risk, and } 5 \% \text { possibly dependent }\end{array}$ & UK & Krska and Mackridge ${ }^{62}$ \\
\hline Interviews & $\begin{array}{l}\text { Clients requesting emergency contraception completed AUDIT: } 22 \text { clients identified as } \\
\text { "low risk" interviewed were positive about service; most of } 53 \text { in "risky" category felt } \\
\text { advice was useful and appropriate to be provided by a pharmacist }\end{array}$ & UK & Brown et $\mathrm{al}^{58}$ \\
\hline $\begin{array}{l}\text { Mixed methods: } \\
\text { survey and } \\
\text { interviews }\end{array}$ & $\begin{array}{l}\text { Twenty-six community pharmacies provided SBI to }|4| \text { consumers who completed } \\
\text { AUDIT-C. Follow-up interviews with } 6 I \text { hazardous/low-risk drinkers showed } \\
\text { significant reduction in 7-day alcohol-unit consumption, but not AUDIT-C scores }\end{array}$ & UK & Khan et $\mathrm{a}^{60}$ \\
\hline Survey & $\begin{array}{l}\text { Cross-sectional, anonymous survey through } 43 \text { randomly selected NZ community } \\
\text { pharmacies. } 2,384 \text { consumers completed AUDIT-C, with } 30 \% \text { considered risky } \\
\text { drinkers. Attitudes to pharmacy SBI were generally positive }\end{array}$ & NZ & Sheridan et $\mathrm{a}^{55}$ \\
\hline Interviews & $\begin{array}{l}\text { Interviews with } 22 \text { English and I } 8 \text { NZ pharmacists. Pharmacists were mostly positive } \\
\text { about pharmacy SBI. Barriers and facilitators identified }\end{array}$ & $\mathrm{NZ}$ and UK & Horsfield et $a^{68}$ \\
\hline Survey & $\begin{array}{l}\text { Survey of all community pharmacies in Scotland, with } 45 \% \text { ( } 487 \text { of } 1,098) \text { response } \\
\text { rate. Knowledge of recommended alcohol-intake limits was high }(84 \%) \text {, but few }(5 \%) \\
\text { advised consumers on alcohol consumption. Approximately } 25 \% \text { were confident in } \\
\text { providing SBI. Mixed views on appropriateness of pharmacy-based SBI services }\end{array}$ & UK & McCaig et $a^{66}$ \\
\hline Interviews & $\begin{array}{l}\text { Interviews with pharmacists from } 43 \mathrm{NZ} \text { pharmacies that handed out surveys to } \\
\text { customers about alcohol use and pharmacy SBI services }\end{array}$ & NZ & Sheridan et $\mathrm{al}^{69}$ \\
\hline $\begin{array}{l}\text { Mixed methods: } \\
\text { survey and } \\
\text { interviews }\end{array}$ & $\begin{array}{l}\text { Purposive sampling to select four London pharmacies. } 237 \text { consumers approached, } 89 \\
\text { completed AUDIT-C, } 5 \text { I (52\%) identified as risky drinkers, } 97 \text { (96\%) willing to discuss } \\
\text { drinking, and } 99(98 \%) \text { to accept information }\end{array}$ & UK & Dhital et $\mathrm{al}^{59}$ \\
\hline Interviews & $\begin{array}{l}\text { Nine pharmacists and } 13 \text { assistants trained over } 2 \text { days. They were positive about } \\
\text { training }\end{array}$ & UK & Fitzgerald et $\mathrm{al}^{57}$ \\
\hline Survey & $\begin{array}{l}\text { Postal survey of community pharmacies, with } 39.1 \% \text { response rate. Participants' } \\
\text { general knowledge of alcohol content of drinks and recommended safe-drinking limits } \\
\text { was poor, but they were motivated to undertake an SBI role }\end{array}$ & NZ & Sheridan et a $\mathrm{a}^{65}$ \\
\hline $\begin{array}{l}\text { Mixed methods: } \\
\text { survey and } \\
\text { interviews }\end{array}$ & $\begin{array}{l}\text { They recruited } 70 \text { clients over } 3 \text { months. FAST used to screen and guide the } \\
\text { intervention: } 30 \text { screened as drinking hazardously ( } 42.9 \%) \text { and seven ( } 10 \%) \text { positive for } \\
\text { harmful drinking; } 19 \text { at 3-month follow-up positive about the experience }\end{array}$ & UK & Fitzgerald et a ${ }^{56}$ \\
\hline
\end{tabular}

Abbreviations: SBI, screening and brief intervention; AUDIT-C, Alcohol Use Disorders Identification Test—consumption (items I-3 from AUDIT); FAST, Fast Alcohol Screening Tool; NZ, New Zealand.

and 8 as "probably dependent" (score $20+$ ) consumers of alcohol. Those scoring $\geq 8$ received brief advice and an alcohol information booklet. ${ }^{64}$ Reactions to the SBI process were generally favorable, and a post-SBI consumer questionnaire showed that $75 \%$ agreed that it was either appropriate or very appropriate for the pharmacist to ask about their alcohol consumption and $88 \%$ reported being comfortable discussing their alcohol consumption with the pharmacist.
Semistructured interviews with 10 participating pharmacists indicated that alcohol SBI was manageable within the community pharmacy setting and fitted well within the scope of practice. The majority commented that AUDIT was helpful as a screening tool and that it aided in initiating a discussion on the customer's alcohol use.

A study by Sheridan et al that surveyed NZ pharmacists showed that their knowledge of alcohol content of alcoholic 
drinks and recommended "low-risk" drinking limits was poor, although participants were keen to take on a role in alcohol SBI. ${ }^{65}$ The study highlighted a need for pharmacystaff training prior in delivering a pharmacy SBI service. A postal survey by McCaig et al to characterize community pharmacists' level of activity and views on alcohol-misuse services sent to all community pharmacies in Scotland achieved a $45 \%$ (497 of 1,098 ) response rate. ${ }^{66}$ Although the pharmacists' knowledge of recommended alcoholintake limits was high, few advised consumers on alcohol consumption. About $40 \%$ lacked confidence in providing alcohol SBI, and they had mixed views on the appropriateness of pharmacist involvement in discussing alcohol use with consumers. Dare et al reported a 2014 focus group study with Perth community pharmacists and found they regarded the provision of alcohol advice as part of a pharmacist's role that could be linked to other professional services, such as dispensing. ${ }^{67}$ However, lack of knowledge, skills, confidence in how to approach consumers, and discussing alcohol use in a nonconfrontational way were identified as barriers, and highlighted a need for specific alcohol-related communication-skill training to be able to raise consumers' alcohol use in a nonconfrontational manner. Other barriers identified were time and financial constraints, similar to previous research by Horsfield et al..$^{50,68}$

Research in NZ and England regarding SBIs with problem drinkers indicated that pharmacists considered there was scope for alcohol-related health promotion in community pharmacies. ${ }^{68,69}$ Participants identified a need for appropriate screening tools and training, whereas barriers to community pharmacy SBIs included concerns about offending or alienating consumers, lack of experience or confidence, workforce pressures, privacy, and remuneration.

Only one of the identified reports used a "strong" study design $(\mathrm{RCT})^{54}$ to assess behavioral outcomes, and it reported no significant effect on alcohol measures at 3 months. In contrast, the remaining 14 studies that addressed more distal issues, such as consumer attitudes and feasibility, were generally positive. Further, these studies showed that community pharmacists were willing to deliver alcohol SBI and advice, but needed to receive relevant training beyond alcohol guidelines that specifically incorporated communication strategies. Overall, the evidence suggests that SBI in community pharmacies is feasible, with positive feedback from consumers, but until interventions are developed that are effective in reducing alcohol-use or alcohol-related harms, it is premature to advocate for their funding.

\section{Alcohol-use screening tools}

There are no validated biomarkers of risky drinking: even among those with an alcohol disorder, biological measures, such as liver function tests, while commonly used clinically, have poor screening characteristics. ${ }^{70}$ Therefore, risky drinkers need to be identified with self-report measures.

The most widely used and extensively validated measure of this type is the 10-item AUDIT. ${ }^{71}$ This was developed by the WHO and has been validated as a screening tool in a range of adult populations. Scores $>7$ are used to identify those with hazardous or harmful levels of alcohol use. Those scoring $\geq 8$ are considered to be "at-risk" of alcohol-related harms. Those scoring $\geq 20$ are likely to have an alcohol-use disorder. It is generally accepted that BIs are less effective for this group ${ }^{72}$ and that they should be advised to seek specialist help or speak to their GP.

AUDIT-C is a validated abbreviated version of the AUDIT consisting of the first three items of the AUDIT ${ }^{73,74}$ to quickly identify those engaged in "risky" alcohol use (females $\geq 3$, males $\geq 4$ ). Those fulfilling these criteria should then complete the remaining AUDIT questions. There have been numerous other alcohol (and other drug)-screening instruments that have been developed. ${ }^{75}$ Details of the screening characteristics and the target populations of 14 leading instruments have been published by the National Institute on Alcohol Abuse and Alcoholism, and the report is freely available to the public. ${ }^{76}$

\section{Screening and brief alcohol interventions}

A review of reviews identified 24 systematic reviews of alcohol SBI in primary care, ${ }^{7}$ and highlighted the extensive data on their effectiveness, particularly for middle-aged men and those with subclinical levels of use. Table 2 is a summary of key research on the topic of SBI for problematic alcohol use in primary care, showing a number of systematic reviews that have been conducted over an extended period. It incorporates the aforementioned review of reviews and also an economic evaluation. Despite the evidence supporting SBI in general practice, many GPs do not routinely assess patients for risky drinking or provide advice to high-risk groups. ${ }^{77,78}$ Providing alcohol SBI in community pharmacies thus offers an alternative primary health-care setting in which to address alcohol-misuse and health-related issues.

As already noted, those with an alcohol disorder are generally referred for intensive intervention. Those with less severe problems are more likely to have intact psychosocial supports and do not generally require the resource-intensive 
Table 2 Key alcohol-screening and brief intervention studies in primary health care

\begin{tabular}{|c|c|c|}
\hline Study type & Short description of research & References \\
\hline $\begin{array}{l}\text { Systematic review of } \\
\text { reviews }\end{array}$ & $\begin{array}{l}\text { 2002-20I 2: } 24 \text { systematic reviews of } 56 \text { trials of SBI in primary care. Extensive evidence supported } \\
\text { benefit for middle-aged males with at-risk drinking: fewer data on other groups }\end{array}$ & O'Donnell et $\mathrm{al}^{7}$ \\
\hline Clinical guideline & $\begin{array}{l}\text { Task force recommended that clinicians screen adults for alcohol misuse and provide risky drinkers } \\
\text { with brief behavioral counseling interventions }\end{array}$ & Moyer 103 \\
\hline Cost-effectiveness & $\begin{array}{l}\text { Model costs of screening all new registrations with family doctors and at next appointment. Both } \\
\text { approaches were cost-effective, eg, saving of } £ 120 \text { m over } 30 \text { years or } £ 6,900 / Q A L Y \text { gained }\end{array}$ & Purshouse et al ${ }^{104}$ \\
\hline Systematic review & $\begin{array}{l}\text { Review of } 22 \text { trials ( } n=7,619) \text { : those receiving SBI had significantly lower alcohol use at } 12 \text { months, } \\
\text { but not successful with the smaller subgroup of eight trials reporting outcomes by sex }\end{array}$ & Kaner et al $\left.\right|^{105}$ \\
\hline Systematic review & $\begin{array}{l}\text { Nineteen trials }(n=5,639) \text { showed mean reduction of } 38 \mathrm{~g} \text { alcohol per week for SBI compared with } \\
\text { controls, with benefits for both males and females at } 6 \text { and } 12 \text { months }\end{array}$ & Bertholet et al ${ }^{106}$ \\
\hline Systematic review & $\begin{array}{l}\text { Thirty-four trials with nontreatment-seeking people. Effect sizes at } 3 \text { months of SBI versus control: } \\
\text { composite measure, } d=0.30 \text {; alcohol consumption, } d=0.67\end{array}$ & Moyer et $\mathrm{al}^{72}$ \\
\hline
\end{tabular}

Abbreviations: SBI, screening and brief intervention; QALY, quality-adjusted life year.

interventions usually needed by those with alcohol dependence. Therefore, identifying and managing people before they develop major physical and/or psychosocial complications is desirable, and the identification of risky alcohol-use consumers is a major goal for SBI. ${ }^{79}$ In addition, opportunistic SBI may reach a proportion of those who would not normally seek help or present at specialist treatment facilities.

There is no universally accepted definition of what constitutes a BI, but one or two sessions of treatment is typical. ${ }^{80}$ Within a primary care setting, interventions can be incorporated within a 5- to 15 -minute consultation. ${ }^{81}$ Box 2 lists five key elements that have been identified for inclusion in an intervention. ${ }^{82}$ Similarly, the components of a BI have been summarized with the acronym FRAMES (personally relevant feedback, client's responsibility for change, objective advice, menu of options, empathic, nonconfrontational approach, and self-efficacy in the client to change their behavior). In addition, these components draw on principles of motivational interviewing, such as empathy, creating ambivalence, rolling with resistance, and reflective listening. Typically, BIs have a goal of harm reduction, rather than abstinence, except where clinically indicated (eg, pregnancy, medication interaction). ${ }^{72,83}$

\section{Discussion}

This narrative review has identified a number of studies that evaluated community pharmacy-delivered alcohol SBI services. Overall consumer attitudes toward community pharmacy alcohol SBI was positive, although some studies identified a consumer need to increase privacy in the pharmacy setting. Pharmacists reported that it was feasible to deliver interventions in this environment, but highlighted training requirements that incorporate communication aspects and specific alcohol information. Over the previous 10 years, there have only been two RCTs to evaluate the
Box 2 Five key elements identified for inclusion in an intervention

I. Assess the quantity and frequency of alcohol usage and provide direct feedback regarding health or psychosocial morbidity relevant to the client

2. Goals for alcohol use are established that are acceptable to both the provider and the client. These goals may be a reduction in consumption, such as using alcohol in a "low-risk" fashion or complete cessation

3. The provider uses behavioral modification techniques, eg, to help the client identify high-risk situations and develop strategies to deal with these

4. The provider should supply support material on problems associated with alcohol use plus self-help techniques

5. The provider should offer ongoing support

Note: Data from Humeniuk et al..$^{82}$

ongoing impact of community pharmacy SBI services, both of these in the UK. Evidence about the impact of pharmacists' interventions from both studies were limited, and further research is thus needed to evaluate the effectiveness and cost-effectiveness of community pharmacy-delivered alcohol-misuse services.

The need to increase privacy was raised in some of the alcohol SBI studies, which is similar to literatures that highlighted community pharmacy privacy needs. ${ }^{84,85}$ However, newer professional services in many countries now require and in some instances mandate pharmacies to have private areas, eg, England and Wales pharmacies prior to $2005 \mathrm{had}$ already required consultation rooms for advanced services ${ }^{86}$ and Australian community pharmacies since 2012 have needed to have a private area to offer government-reimbursed in-pharmacy medication-review services ${ }^{87}$ and pharmacistadministered influenza-vaccination services ${ }^{88,89}$ This space is also used to discuss confidential and sensitive issues with consumers ${ }^{90}$ and conduct screening services (ie, blood pressure measurements) and could be used for SBI and provision of alcohol-related services. 
The role of community pharmacists in the provision of ongoing support for consumers with mental illness is a growing service, with evidence showing positive consumer impact. ${ }^{91,92}$ Delivering support for mental health consumers through community pharmacies has revealed that trusting relationships among consumers, carers, and pharmacy staff underpin perceptions of the pharmacy as a safe health space where consumers feel comfortable sharing personal information, ${ }^{44}$ with positive consumer outcomes ${ }^{46}$ Alcohol misuse is classified as a mental health condition ${ }^{93}$ and thus sits well with the role that community pharmacists play in terms of screening as well as disease state management services. Community pharmacists are thus in an ideal position to provide alcohol SBI and support.

Community pharmacies provide accessible and affordable health care, while consumers have control over the level of engagement with the staff. ${ }^{37}$ Research has demonstrated that the public see pharmacists as trustworthy medicine experts and reliable advisors on health matters with collaborative relationships with the medical profession..$^{37,44,94}$ From a consumer perspective, an Australian study that involved intervention preferences of rural communities showed that community pharmacy alcohol interventions were indeed acceptable. ${ }^{95}$ Community pharmacy alcohol services could thus particularly benefit rural and remote populations.

Appropriate training to equip pharmacists with knowledge to conduct alcohol SBI that also provides skills in advanced communication aspects, such as motivational interviewing, was identified by pharmacists in several studies. ${ }^{54,65,67}$ Any alcohol intervention study should thus incorporate training to ensure pharmacists are confident in the provision of the service. Lessons could be used from other studies that evaluated the training of pharmacists in motivational interviewing to address other behavior changes, such as smoking cessation ${ }^{47-49}$ and weight management, ${ }^{39}$ that incorporated behavioral therapy/modification with positive results. Other community pharmacy interventions have shown positive behavior change results for diabetes, asthma, and cardiovascular disease through the use of repeated assessment, management, monitoring, and review. ${ }^{96-98}$

Even though there is a strong evidence base for the use of SBI in primary care settings, ${ }^{7}$ when a person scores below the screening threshold, pharmacy staff should also include additional information they already hold or can observe about that person (eg, current mediations, pregnancy status, other health issues) in deciding if an intervention is warranted. However, it is important not to use stereotypes of potential at-risk drinkers in targeting customers for screening. Nevertheless, where comprehensive screening is not feasible, some studies have used requests for key medications as a means of increasing the yield from screening and as a way of starting a discussion about lifestyle factors, including alcohol use. ${ }^{63}$

This review focused on the role of community pharmacists in alcohol intervention studies. The strength of this review lies in it being a comprehensive review of topics amid the lack of RCTs about the impact of community pharmacy alcohol SBI services. However, as this is a narrative rather than a systematic review, it is possible that not all studies on community pharmacy alcohol services were incorporated.

\section{Conclusion}

The literature provides some evidence to support the potential role of community pharmacy alcohol interventions. However, a critical consideration at this stage is that neither of the two RCTs on the topic reported reductions in alcohol measures to support their use. ${ }^{24,54}$ The community pharmacy setting has unique benefits in reaching a population unlikely to present for treatment, but one where people who are unwilling to discuss their use of alcohol can easily transfer their custom to another pharmacy. Nevertheless, the prevalence of risky alcohol use internationally means that increasing the number of people receiving SBI, including in novel settings, needs to be a public health priority. Furthermore, health authorities are now commissioning community pharmacies to undertake alcohol interventions. ${ }^{99}$ Therefore, it is essential that any concerns about their effectiveness are resolved before they are routinely implemented to ensure that scare health funds are not wasted.

\section{Author contributions}

HLH initiated the review and led the writing of the community pharmacy aspects of the paper. RJT was responsible for the alcohol-related content. Both authors contributed toward data analysis, drafting and critically revising the paper, gave final approval of the version to be published, and agree to be accountable for all aspects of the work.

\section{Disclosure}

RJT is supported by funding from the Australian government under the Substance Misuse Prevention and Service Improvement Grants Fund through employment at the National Drug 
Research Institute at Curtin University. The authors report no other conflicts of interest in this work.

\section{References}

1. World Health Organization. Global Status Report on Alcohol and Health 2014. Geneva: WHO; 2014

2. Proude EM, Lopatko O, Lintzeris N, Haber P. The Treatment of Alcohol Problems: A Review of the Evidence. Canberra: Department of Health and Ageing; 2009.

3. Poikolainen K, Paljärvi T, Mäkelä P. Alcohol and the preventive paradox: serious harms and drinking patterns. Addiction. 2007;102(4):571-578.

4. Saunders JB, Lee NK. Hazardous alcohol use: its delineation as a subthreshold disorder, and approaches to its diagnosis and management. Compr Psychiatry. 2000;41(2 Suppl 1):95-103.

5. Cohen E, Feinn R, Arias A, Kranzler HR. Alcohol treatment utilization: findings from the National Epidemiologic Survey on Alcohol and Related Conditions. Drug Alcohol Depend. 2007;86(2-3):214-21.

6. Monti P, Tevyaw, TO, Borsari B. Drinking among young adults: screening, brief intervention, and outcome. Alcohol Res Health. 2004;28(4):236-244.

7. O'Donnell A, Anderson P, Newbury-Birch D, et al. The impact of brief alcohol interventions in primary healthcare: a systematic review of reviews. Alcohol Alcohol. 2014;49(1):66-78.

8. World Health Organization. Public health problems caused by harmful use of alcohol; 2005. Available from: http://www.who.int/substance_abuse/activities/public_health_alcohol/en. Accessed March 22, 2018.

9. Collins DJ, Lapsley HM. The Costs of Tobacco, Alcohol and Illicit Drug Abuse to Australian Society in 2004/05. Canberra: Department of Health; 2008.

10. Laslett AM, Catalano P, Chikritzhs Y, et al. The Range and Magnitude of Alcohol's Harm to Others. Canberra: Alcohol Education and Rehabilitation Foundation; 2010.

11. National Health and Medical Research Council. Australian Guidelines to Reduce Health Risks from Drinking Alcohol. Canberra: NHMRC; 2009.

12. Australian Institute of Health and Welfare. 2016 National Drug Strategy Household Survey. Canberra: AIHW; 2017.

13. Teesson M, Hall W, Slade T, et al. Prevalence and correlates of DSM-IV alcohol abuse and dependence in Australia: findings of the 2007 National Survey of Mental Health and Wellbeing. Addiction. 2010;105(12):2085-2094.

14. Chikritzhs T, Stockwell T, Naimi T, Andreasson S, Dangardt F, Liang W. Has the leaning tower of presumed health benefits from 'moderate' alcohol use finally collapsed? Addiction. 2015;110(5):726-727.

15. World Health Organization. The World Health Report 2008: Primary Health Care-Now More Than Ever. Geneva: WHO; 2008.

16. World Health Organization. Achieving better health outcomes and efficiency gains through rational use of medicine; 2011. Available from: http://apps.who.int/medicinedocs/en/m/abstract/Js17575en. Accessed March 22, 2018.

17. Pharmaceutical Society of Australia. Standards for the provision of pharmacy medicines and pharmacist only medicines in community pharmacy; 2005. Available from: http://www.psa.org.au/download/ standards/s2s3-standards.pdf. Accessed March 22, 2018.

18. Pharmaceutical Society of Australia. Australian Pharmaceutical Formulary and Handbook: The Everyday Guide to Pharmacy Practice. 23rd ed. Canberra: PSA; 2015.

19. Higgins SJ, Hattingh HL. Requests for emergency contraception in community pharmacy: an evaluation of services provided to mystery patients. Res Social Adm Pharm. 2013;9(1):114-119.

20. Pharmaceutical Society of Australia. National Competency Standards Framework for Pharmacists in Australia. Canberra: PSA; 2010.
21. Australian Institute of Health and Welfare. Mental health-related prescriptions; 2014. Available from: https://www.aihw.gov.au/reports/ mental-health-services/mental-health-services-in-australia/archivedreports-and-data. Accessed March 22, 2018.

22. World Health Organization. WHO Collaborative Project on Identification and Management of Alcohol-Related Problems in Primary Health Care. Geneva: WHO; 2006.

23. Brown TJ, Todd A, O'Malley C, et al. Community pharmacy-delivered interventions for public health priorities: a systematic review of interventions for alcohol reduction, smoking cessation and weight management, including meta-analysis for smoking cessation. $B M J$ Open. 2016;6(2):e009828.

24. Watson MC, Blenkinsopp A. The feasibility of providing community pharmacy-based services for alcohol misuse: a literature review. Int $J$ Pharm Pract. 2009;17(4):199-205.

25. Mossialos E, Courtin E, Naci H, et al. From "retailers" to health care providers: transforming the role of community pharmacists in chronic disease management. Health Policy. 2015;119(5):628-639.

26. Pharmaceutical Society of Australia. A framework for pharmacists as partners in mental health care; 2013. Available from: http://www. psa.org.au/download/policies/mental-health-framework.pdf. Accessed March 22, 2018.

27. Australian Medicines Handbook. Adelaide: AMH; 2016.

28. Australian Institute of Health and Welfare. Australia's Health 2014. Canberra: AIHW; 2014.

29. Boden JM, Fergusson DM. Alcohol and depression. Addiction. 2011;106(5):906-914.

30. Regier DA, Farmer ME, Rae DS, et al. Comorbidity of mental disorders with alcohol and other drug abuse: results from the Epidemiologic Catchment Area (ECA) study. JAMA. 1990;264(19):2511-2518.

31. Marel C, Mills KL, Kingston R, et al. Guidelines on the Management of Co-occurring Alcohol and Other Drug and Mental Health Conditions in Alcohol and Other Drug Treatment Settings. 2nd ed. Sydney: Centre of Research Excellence in Mental Health and Substance Use; 2016.

32. Cousins G, Galvin R, Flood M, et al. Potential for alcohol and drug interactions in older adults: evidence from the Irish longitudinal study on ageing. BMC Geriatr. 2014;14:57.

33. Pringle KE, Ahern FM, Heller DA, Gold CH, Brown TV. Potential for alcohol and prescription drug interactions in older people. $J \mathrm{Am}$ Geriatr Soc. 2005;53(11):1930-1936.

34. Mohanty M. Alcohol and Medication Use in Community-Dwelling Older Adults: Understanding the Effect of Alcohol and Central Nervous System-Acting Medications on the Risk for Falls [doctoral thesis]. Richmond: Virginia Commonwealth University; 2013.

35. Swift W, Stollznow N, Pirotta M. The use of alcohol and medicines among Australian adults. Aust N Z J Public Health. 2007;31(6):529-532.

36. Wilkinson C, Dare J, French M, McDermott M, Lo J, Allsop S. Prescribing or dispensing medication represents the best opportunity for GPs and pharmacists to engage older people in alcohol-related clinical conversations. Int J Pharm Pract. 2016;24(5):319-325.

37. Benrimoj S, Frommer M. Community pharmacy in Australia. Aust Health Rev. 2004;28(2):238-246.

38. Brown D, Portlock J, Rutter P, Nazar Z. From community pharmacy to healthy living pharmacy: positive early experiences from Portsmouth, England. Res Social Adm Pharm. 2014;10(1):72-87.

39. Kellow N. Evaluation of a rural community pharmacy-based waist management project: bringing the program to the people. Aust J Prim Health. 2011;17(1):16-22.

40. Gilbert A, Roughead E, Beilby J, Mott K, Barratt J. Collaborative medication management services: improving patient care. Med J Aust. 2002;177(4):189-192.

41. George P, Molina J, Cheah J, Chan S, Lim B. The evolving role of the community pharmacist in chronic disease management: a literature review. Ann Acad Med Singapore. 2010;39(11):861-867. 
42. Armour CL, Smith L, Krass I. Community pharmacy, disease state management, and adherence to medication: a review. Dis Manag Health Outcomes. 2008;16(4):245-254.

43. Blalock SJ, Roberts AW, Lauffenburger JC, Thompson T, O'Connor SK. The effect of community pharmacy-based interventions on patient health outcomes: a systematic review. Med Care Res Revi. 2013;70(3):235-266.

44. Mey A, Knox K, Kelly F, et al. Trust and safe spaces: mental health consumers' and carers' relationships with community pharmacy staff. Patient. 2013;6(4):281-289.

45. Blenkinsopp A, Anderson C, Armstrong M. Systematic review of the effectiveness of community pharmacy-based interventions to reduce risk behaviours and risk factors for coronary heart disease. J Public Health. 2003;25(2):144-153.

46. Wheeler A, Fowler J, Hattingh L, Kelly F. Exploring the role of community pharmacy in supporting mental health consumers and carers. 2015. Available from: http://6cpa.com.au/resources/fifth-agreement-rd/ mental-health-project/. Accessed March 22, 2018.

47. Dent L, Harris K, Noonan C. Randomized trial assessing the effectiveness of a pharmacist-delivered program for smoking cessation. Ann Pharmacother. 2009;43(2):194-201.

48. Patwardhan P, Chewning B. Effectiveness of intervention to implement tobacco cessation counseling in community chain pharmacies. $J \mathrm{Am}$ Pharm Assoc (2003). 2012;52(4):507-514.

49. Purcell J, Farris K, Aquilino M. Feasibility of brief smoking cessation intervention in community pharmacies. J Am Pharm Assoc (2003). 2006;46(5):616-618.

50. Agomo CO. The role of community pharmacists in public health: a scoping review of the literature. J Pharm Health Serv Res. 2012;3(1):25-33.

51. Saramunee K, Krska J, Mackridge A, Richards J, Suttajit S, PhillipsHoward P. General public's views on pharmacy public health services: current situation and opportunities in the future. Public Health. 2015;129(6):705-715.

52. Joyce AW, Sunderland VB, Burrows S, McManus A, Howat P, Maycock B. Community pharmacy's role in promoting healthy behaviours. J Pharm Health Pract Res. 2007;37(1):42-44.

53. Watson M, Inch J, Jaffray M, Stewart D. Screening and brief interventions for alcohol misuse delivered in the community pharmacy setting: a pilot study. Int J Pharm Pract. 2011;19 (Suppl 1):5.

54. Dhital R, Norman I, Whittlesea C, Murrells T, McCambridge $\mathrm{J}$. The effectiveness of brief alcohol interventions delivered by community pharmacists: randomized controlled trial. Addiction. 2015;110(10):1586-1594.

55. Sheridan J, Stewart J, Smart RO, McCormick R. Risky drinking among community pharmacy customers in New Zealand and their attitudes towards pharmacist screening and brief interventions. Drug Alcohol Rev. 2012;31(1):56-63.

56. Fitzgerald N, McCaig DJ, Watson H, Thomson D, Stewart DC. Development, implementation and evaluation of a pilot project to deliver interventions on alcohol issues in community pharmacies. Int J Pharm Pract. 2008;16(1):17-22.

57. Fitzgerald N, Watson H, McCaig D, Stewart D. Developing and evaluating training for community pharmacists to deliver interventions on alcohol issues. Pharm World Sci. 2009;31(2):149-153.

58. Brown S, Henderson E, Sullivan C. The feasibility and acceptability of the provision of alcohol screening and brief advice in pharmacies for women accessing emergency contraception: an evaluation study. BMC Public Health. 2014;14:1139.

59. Dhital R, Whittlesea CM, Norman IJ, Milligan P. Community pharmacy service users' views and perceptions of alcohol screening and brief intervention. Drug Alcohol Rev. 2010;29(6):596-602.

60. Khan NS, Norman IJ, Dhital R, McCrone P, Milligan P, Whittlesea $\mathrm{CM}$. Alcohol brief intervention in community pharmacies: a feasibility study of outcomes and customer experiences. Int J Clin Pharm. 2013;35(6):1178-1187.
61. Dhital R, Norman I, Whittlesea C, McCambridge J. Effectiveness of alcohol brief intervention delivered by community pharmacists: study protocol of a two-arm randomised controlled trial. BMC Public Health. 2013;13:152.

62. Krska J, Mackridge AJ. Involving the public and other stakeholders in development and evaluation of a community pharmacy alcohol screening and brief advice service. Public Health. 2014;128(4):309-316.

63. Hattingh HL, Hallett J, Tait RJ. 'Making the invisible visible' through alcohol screening and brief intervention in community pharmacies: an Australian feasibility study. BMC Public Health. 2016;16:1141.

64. Western Australian Alcohol and Drug Authority. Here's To Your Health: A Guide to Reducing Alcohol-Related Risks and Harms. Perth: Drug and Alcohol Office; 2011.

65. Sheridan J, Wheeler A, Chen LJ, Huang AC, Leung IN, Tien KY. Screening and brief interventions for alcohol: attitudes, knowledge and experience of community pharmacists in Auckland, New Zealand. Drug Alcohol Rev. 2008;27(4):380-387.

66. McCaig D, Fitzgerald N, Stewart D. Provision of advice on alcohol use in community pharmacy: a cross-sectional survey of pharmacists' practice, knowledge, views and confidence: alcohol advice in community pharmacy. Int J Pharm Pract. 2011;19(3):171-178.

67. Dare J, Wilkinson C, Garlepp M, Lo J, Allsop S. Community pharmacists require additional support to develop capacity in delivering alcohol-related health information to older adults. Int J Pharm Pract. 2017;25(4):301-310.

68. Horsfield E, Sheridan J, Anderson C. What do community pharmacists think about undertaking screening and brief interventions with problem drinkers? Results of a qualitative study in New Zealand and England. Int J Pharm Pract. 2011;19(3):192-200.

69. Sheridan J, Smart R, McCormick R. Estimating problem drinking among community pharmacy customers: what did pharmacists think of the method? Int J Pharm Pract. 2010;18(5):290-296.

70. Conigrave KM, Degenhardt LJ, Whitfield JB, Saunders JB, Helander A, Tabakoff B. CDT, GGT, and AST as markers of alcohol use: the WHO/ISBRA collaborative project. Alcohol Clin Exp Res. 2002;26(3):332-339.

71. Saunders JB, Aasland OG, Babor TF, de la Fuente JR, Grant M. Development of the Alcohol Use Disorders Identification Test (AUDIT): WHO collaborative project on early detection of persons with harmful alcohol consumption-II. Addiction. 1993;88(6):791-804.

72. Moyer A, Finney JW, Swearingen CE, Vergun P. Brief interventions for alcohol problems: a meta-analytic review of controlled investigations in treatment-seeking and non-treatment-seeking populations. Addiction. 2002;97(3):279-292.

73. Bush K, Kivlahan DR, McDonell MB, Fihn SD, Bradley KA. The AUDIT alcohol consumption questions (AUDIT-C): an effective brief screening test for problem drinking. Arch Intern Med. 1998;158(16):1789-1795.

74. Bradley KA, Bush KR, Epler AJ, et al. Two brief alcohol-screening tests from the Alcohol Use Disorders Identification Test (AUDIT): validation in a female Veterans Affairs patient population. Arch Intern Med. 2003;163(7):821-829.

75. Babor TF, McRee BG, Kassebaum PA, Grimaldi PL, Ahmed K, Bray J. Screening, brief intervention, and referral to treatment (SBIRT): toward a public health approach to the management of substance abuse. Subst Abus. 2007;28(3):7-30.

76. Connors GJ, Volk RJ. Self-report screening for alcohol problems among adults. In: Allen JP, Wilson VB, editors. Assessing Alcohol Problems: A Guide for Clinicians and Researchers. 2nd ed. Bethesda: National Institute on Alcohol Abuse and Alcoholism; 2003:21-35.

77. Tam CW, Zwar N, Markham R. Australian general practitioner perceptions of the detection and screening of at-risk drinking, and the role of the AUDIT-C: a qualitative study. BMC Fam Pract. 2013;14:121.

78. Cheeta S, Drummond C, Oyefeso A, et al. Low identification of alcohol use disorders in general practice in England. Addiction. 2008;103(5):766-773 
79. Tait RJ, Hulse GK. Brief interventions for the treatment of alcohol or other drug addiction. In: Johnson B, editor. Addiction Medicine: Science and Practice. Heidelberg: Springer; 2010:783-796.

80. Miller WR, Wilbourne PL. Mesa Grande: a methodological analysis of clinical trials of treatments for alcohol use disorders. Addiction. 2002;97(3):265-277.

81. Centers for Disease Control and Prevention. Planning and Implementing Screening and Brief Intervention for Risky Alcohol Use: A Step-by-Step Guide for Primary Care Practices. Atlanta: CDC; 2014.

82. Humeniuk R, Henry-Edwards S, Ali R, Poznyak V, Monteiro M. The ASSIST-Linked Brief Intervention for Hazardous and Harmful Substance Use. Geneva: World Health Organization; 2010.

83. Rollnick S, Miller W. What is motivational interviewing? Behav Cogn Psychother. 1995;23(4):325-334.

84. Hattingh HL, Knox K, Fejzic J, et al. Privacy and confidentiality: perspectives of mental health consumers and carers in pharmacy settings. Int J Pharm Pract. 2015;23(1):52-60.

85. Hattingh HL, Emmerton L, Tin PN, Green C. Utilization of community pharmacy space to enhance privacy: a qualitative study. Health Expect. 2016;19(5):1098-1110.

86. Buisson J. How to make space for a consultation room in your community pharmacy. Pharm J. 2005;275(7378):689-691.

87. Department of Health and Ageing. program Specific Guidelines MedsCheck and Diabetes MedsCheck. Canberra: Department of Health and Ageing; 2012.

88. Government of Western Australia. Pharmacist vaccination code; 2014. Available from: http://www.pharmacyboard.gov.au/Codes-Guidelines. aspx. Accessed March 23, 2018.

89. Queensland Department of Health. Queensland pharmacist vaccination standard; 2016. Available from: https://www.health.qld.gov.au/_data/ assets/pdf_file/0016/444130/standard-pharmacy-vaccination.pdf. Accessed March 23, 2018.

90. Higgins SJ, Hattingh HL. Requests for emergency contraception in community pharmacy: an evaluation of services provided to mystery patients. Res Social Adm Pharm. 2013;9(1):114-119.

91. Hattingh HL, Kelly F, Fowler J, Wheeler AJ. Implementation of a mental health medication management intervention in Australian community pharmacies: facilitators and challenges. Res Social Adm Pharm. 2017;13(5):969-979.

92. McMillan SS, Kelly F, Hattingh HL, Fowler JL, Mihala G, Wheeler AJ. The impact of a person-centred community pharmacy mental health medication support service on consumer outcomes. J Ment Health. 2018;27(2):164-173.

93. Cooper R. Diagnosing the Diagnostic and Statistical Manual of Mental Disorders. London: Karnac Books; 2014.
94. University of South Australia. Consumer experiences, needs and expectations of community pharmacy; 2005. Available from: http://6cpa. com.au/resources/third-agreement/consumer-experiences-needs-andexpectations-of-community-pharmacy. Accessed March 23, 2018.

95. Shakeshaft A, Petrie D, Doran C, Breen C, Sanson-Fisher R. An empirical approach to selecting community-based alcohol interventions: combining research evidence, rural community views and professional opinion. BMC Public Health. 2012;12:25.

96. Krass I, Delaney C, Glaubitz S, Kanjanarach T. Measuring patient satisfaction with diabetes disease state management services in community pharmacy. Res Social Adm Pharm. 2009;5(1):31-39.

97. Armour C, Bosnic-Anticevich S, Brillant M, et al. Pharmacy Asthma Care Program (PACP) improves outcomes for patients in the community. Thorax. 2007;62(6):496-502.

98. McNamara KP, O’Reilly SL, Dunbar JA, et al. A pilot study evaluating multiple risk factor interventions by community pharmacists to prevent cardiovascular disease: the PAART CVD Pilot project. Ann Pharmacother. 2012;46(2):183-191.

99. Mackridge AJ, Gray NJ, Krska J. A cross-sectional study using freedom of information requests to evaluate variation in local authority commissioning of community pharmacy public health services in England. BMJ Open. 2017;7(7):e015511.

100. World Health Organization. Lexicon of alcohol and drug terms published by the World Health Organization; 2017. Available from: http://www.who.int/substance_abuse/terminology/who_lexicon/en. Accessed March 23, 2018.

101. World Health Organization. The ICD-10 Classification of Mental and Behavioural Disorders: Diagnostic Criteria for Research. Geneva: WHO; 1993.

102. American Psychiatric Association. Diagnostic and Statistical Manual Of Mental Disorders. 5th ed. Washington: APA; 2013.

103. Moyer VA. Screening and behavioral counseling interventions in primary care to reduce alcohol misuse: U.S. Preventive Services Task Force recommendation statement. Ann Intern Med. 2013;159(3): 210-218.

104. Purshouse RC, Brennan A, Rafia R, et al. Modelling the cost-effectiveness of alcohol screening and brief interventions in primary care in England. Alcohol Alcohol. 2013;48(2):180-188.

105. Kaner EF, Dickinson HO, Beyer FR, et al. Effectiveness of brief alcohol interventions in primary care populations. Cochrane Database Syst Rev. 2007;(2):CD004148.

106. Bertholet N, Daeppen J-B, Wietlisbach V, Fleming M, Burnand B. Reduction of alcohol consumption by brief alcohol intervention in primary care: systematic review and meta-analysis. Arch Intern Med. 2005;165(9):986-995.
Integrated Pharmacy Research and Practice

\section{Publish your work in this journal}

Integrated Pharmacy Research and Practice is an international, peer-reviewed, open access, online journal, publishing original research, reports, reviews and commentaries on all areas of academic and professional pharmacy practice. This journal aims to represent the academic output of pharmacists and pharmacy practice with particular focus on integrated care. All papers are carefully

\section{Dovepress}

peer reviewed to ensure the highest standards as well as ensuring that we are informing and stimulating pharmaceutical professionals. The manuscript management system is completely online and includes a very quick and fair peer-review system, which is all easy to use. Visit http://www.dovepress.com/ testimonials.php to read real quotes from published authors. 